\title{
Diagnóstico técnico da infraestrutura pós-ocupação de regiões periféricas de marabá e proposta da criação de habitações de interesse social (HIS) nessas regiões
}

A existência de áreas de ocupação indevida, geralmente instituídas nas periferias das grandes cidades, tem se tornado cada vez mais frequentes. 0 crescimento desordenado de municípios geralmente leva ao surgimento de aglomerados habitacionais com pouco controle por parte dos órgãos competentes. Segundo o 'Plano Diretor Participativo', Marabá está oficialmente subdividida em dezessete distritos. Destes, seis são urbanos pois se encontram na sede do município; os outros onze se encontram na zona rural, sendo, portanto, distritos rurais. 0 número de bairros dentro do perímetro urbano chega a 96, segundo dados da Prefeitura Municipal de Marabá. Em sua grande maioria, os bairros mais recentes se encontram em regiões periféricas, e são oriundos de invasões territoriais. Esses bairros geralmente não dispõem de infraestrutura apropriada e tampouco dispõe de habitaç̃os minimamente necessárias à subsistência humana. É objetivo deste trabalho o desenvolvimento de um diagnóstico técnico da infraestrutura pós-ocupação de regiões periféricas de Marabá, objetivando a elaboração de uma proposta da criação de habitações de interesse social (HIS) nessas regiões. Serão trabalhados os dados referentes aos seguintes pontos: perfil sociodemográfico e econômico dos moradores; pesquisa de satisfação em relação à unidade habitacional atual; levantamento de modificações necessárias nas unidades habitacionais; e levantamento de principais defeitos (patologias das construções) de partes externas das casas. Por conseguinte, será elaborada uma proposta de criação de HIS nessas regiões, como forma de substituir habitações inadequadas, que deverá ser encaminhada ao poder público responsável.

Palavras-chave: Habitações de Interesse Social; Conforto Térmico; HIS.

\section{Technical diagnosis of the post-occupation infrastructure of peripheral regions of Maraba and proposal for the creation of social housing (HIS) in these regions}

The existence of areas of improper occupation, generally established on the outskirts of large cities, has become increasingly frequent. The disorderly growth of municipalities usually leads to the emergence of housing clusters with little control by the competent agencies. According to the 'Participatory Master Plan', Maraba is officially subdivided into seventeen districts. Of these, six are urban because they are in the headquarters of the municipality; the other eleven are in rural areas and are therefore rural districts. The number of neighborhoods within the urban perimeter reaches 96, according to data from Marabá City Hall. Most of the newer neighborhoods are in outlying regions, and come from territorial invasions. These neighborhoods generally lack adequate infrastructure, nor do they have housing that is minimally necessary for human subsistence. The objective of this work is the development of a technical diagnosis of the post-occupation infrastructure of peripheral regions of Marabá, aiming at the elaboration of a proposal for the creation of social housing (HIS) in these regions. Data will be worked on the following points: socio-demographic and economic profile of residents; satisfaction survey in relation to the current housing unit; survey of necessary modifications in housing units; and survey of major defects (pathologies of buildings) of external parts of houses. Therefore, a proposal for the creation of HIS in these regions will be made as a way to replace inadequate housing, which should be forwarded to the responsible government.

Keywords: Social Interest Dwellings; Thermal comfort; HIS.

Topic: Engenharia Civil

Reviewed anonymously in the process of blind peer

Bruna Vieira Silva iti

Universidade Federal do Sul e Sudeste do Pará, Brasi http://lattes.cnpq.br/8580418914977160

http://orcid.org/0000-0002-6099-0574

bruna.vieira@unifesspa.edu.br

Lygia Maria Policarpio Ferreira (it)

Universidade Federal do Sul e Sudeste do Pará, Brasi

http://lattes.cnpq.br/9330364336746799

http://orcid.org/0000-0002-8956-3963

Ipolicarpio@unifesspa.edu.b

Nuria Pérez Gallardo (iD

Universidade Federal do Sul e Sudeste do Pará, Brasil

http://lattes.cnpq.br/8695660515236363

http://orcid.org/0000-0001-7941-7367

nuria_perez@unifesspa.edu.br
Received: 05/11/2019

Approved: 17/12/2019

Denilson Costa da Silva

Universidade Federal do Sul e Sudeste do Pará, Brasil

http://lattes.cnpq.br/5378575272263741

http://orcid.org/0000-0003-4382-394X

engcsdenilson@gmail.com
Referencing this:

SILVA, B. V.; FERREIRA, L. M. P.; GALLARDO, N. P.; SILVA, D. C.. Diagnóstico técnico da infraestrutura pós-ocupação de regiões periféricas de marabá e proposta da criação de habitações de interesse social (HIS) nessas regiões. Technology Science, v.2, n.1, p.23-27, 2020. DOI: http://doi.org/10.6008/CBPC26746425.2020 .001 .0004 
Diagnóstico técnico da infraestrutura pós-ocupação de regiões periféricas de marabá e proposta da criação de habitações de interesse social

\section{INTRODUÇÃO}

Cidades poli nucleadas apresentam uma forte tendência a um crescimento horizontal. Marabá não foge a essa regra, sendo está uma das maiores e mais importantes cidades do estado, alcançando nos últimos anos um grande crescimento em virtude da proposta de expansão do setor industrial da cidade. Em virtude dessa expansão, cresceram também as regiões periféricas da cidade, aglomerando grande parte da população de baixa renda. De maneira geral as condições de infraestrutura desses novos bairros são muito deficientes, não atendendo as condições básicas necessárias a dignidade humana.

Com a criação do Programa Minha Casa Minha Vida (PMCMV) em 2009, pelo Governo Federal, demandado pelo alto déficit habitacional brasileiro, o assunto tem sido alvo de pesquisas (GRANJA et al., 2009; BRANDÃO, 2011; BONATTO et al., 2011; CONCEIÇÃO et al., 2015), com fins de oferta de um produto com qualidade, que agregue valor e, que seja capaz de proporcionar conforto e bem-estar ao morador - fato que justifica a importância do tema. Uma das limitações apontadas por vários pesquisadores como Hirata (2009) e Rolnik et al. (2015) em relação ao PMCMV, é quanto a localização dessas habitações. Normalmente localizadas em conjuntos habitacionais relativamente longe dos centros urbanos, os empreendimentos geralmente causam um sério desconforto quanto a locomoção, uma vez que raramente é disponibilizado transporte urbano para essas regiões. Desta maneira, o que acontece com grande frequência é o eventual abandono dessas residências, tornando o empreendimento subutilizado.

Marabá conta com 92 bairros, segundo o Plano Diretor do Município, além disso, conta com alguns loteamentos urbanizados inseridos no contexto de conjuntos habitacionais, dois deles são os conjuntos: Jardim do Éden e Tiradentes. Apesar de estarem próximos à BR-155, que Ihes dá acesso, a articulação destes espaços com o restante da cidade, por meio dos deslocamentos de seus habitantes, é dificultada à medida que o transporte público coletivo não consegue atender a demanda criada com a instalação destes conjuntos (SOUZA, 2016), o que reforça a problemática de inserção urbana desses conjuntos habitacionais.

Portanto, o presente trabalho levanta uma questão diferente, propondo que sejam feitos investimentos diferenciados nas habitações periféricas com o objetivo de torná-las mais adequadas ao uso, ao invés de investir um valor relativamente elevado em conjuntos habitacionais onde as famílias não permanecerão por muito tempo através do desenvolvimento de um diagnóstico técnico da infraestrutura pós-ocupação de regiões periféricas de Marabá, objetivando a elaboração de uma proposta de criação de habitações de interesse social (HIS) nessas regiões.

\section{MATERIAIS E MÉTODOS}

A metodologia do seguinte trabalho consistiu, inicialmente, na definição das áreas de interesse, sendo selecionados os bairros Residencial Jardim do Éden e Residencial Tiradentes, ambos bairros frutos de projetos habitacionais pertencentes ao programa Minha Casa, Minha Vida. Os bairros selecionados foram mapeados com auxílio de Sistemas de Posicionamento Global - GPS e bancos de dados locais. 
Diagnóstico técnico da infraestrutura pós-ocupação de regiões periféricas de marabá e proposta da criação de habitações de interesse social

Sequencialmente, foi elaborado um questionário para diagnóstico geral composto por 19 questões abordando critérios como o perfil socioeconômico dos moradores, situação estrutural e funcional das unidades habitacionais, inserção urbana dos conjuntos habitacionais analisados e o grau de satisfação dos moradores. Em seguida, foram realizadas visitas in loco para aplicação do questionário, utilizando-se da técnica de amostragem aleatória simples. Nesta etapa 28 formulários foram aplicados.

A partir das estatísticas obtidas nos estudos iniciais, foram aplicados novos questionários abordando especificamente os principais problemas apontados nas avaliações iniciais e a interação dos moradores com esses problemas, de forma a refinar os resultados e auxiliar o desenvolvimento do novo projeto. Após obtidos esses dados, será proposto um modelo de Habitação de Interesse Social, com base nos critérios dominantes em requisitos do usuário identificados, como por exemplo: (a) requisitos de conformidade (que inclui, os requisitos de localização, espaço e serviço); (b) requisitos de desempenho (condições internas, vida útil, segurança, adaptabilidade, conforto, estética, acessibilidade e circulação); (c) requisitos de meio ambiente (sustentabilidade); (d) requisitos de custos (custos e preços); (e) requisito sistemas que englobam os sistemas elétricos e os sistemas hidrossanitários.

\section{RESULTADOS E DISCUSSÃO}

Com relação a inserção urbana, ambos os residenciais apresentaram resultados negativos na maioria dos critérios avaliados, em destaque, fatores como ausência de postos de saúde e creches próximos, isolamento dos conjuntos habitacionais em relação aos demais núcleos do município e segurança pública. Esses dados reforçam o panorama geral dos conjuntos habitacionais implantados pelo PMCMV já apontado por outros autores. O fator de isolamento percebido pelo usuário é um dos principais responsáveis pelo abandono dessas edificações, sendo esse um problema facilmente diagnosticado em ambos os residenciais analisados. Vale notar que esse abandono é visivelmente maior no bairro Residencial Tiradentes, uma vez que ele é completamente isolado de outros bairros. O mesmo não ocorre de forma tão expressiva no Residencial Jardim do Éden, uma vez que o conjunto é vizinho ao bairro Morada Nova e, portanto, é atendido pela estrutura urbana pré-existente.

Com relação as edificações, os principais problemas apontados pela população foram o conforto térmico e problemas de umidade: $93 \%$ dos entrevistados afirmaram problemas com a alta temperatura no interior das residências durante a maior parte do ano e $64 \%$ apontaram graves problemas com infiltração durante o período chuvoso, como mostram as figuras 1 e 2 . Os problemas de infiltração apontados pelos moradores estão intrinsecamente ligados a própria sazonalidade climática da região unida a falta de manutenção das edificações, sendo esse problema facilmente solucionado com adequações no projeto e atenção no processo de manutenção. 


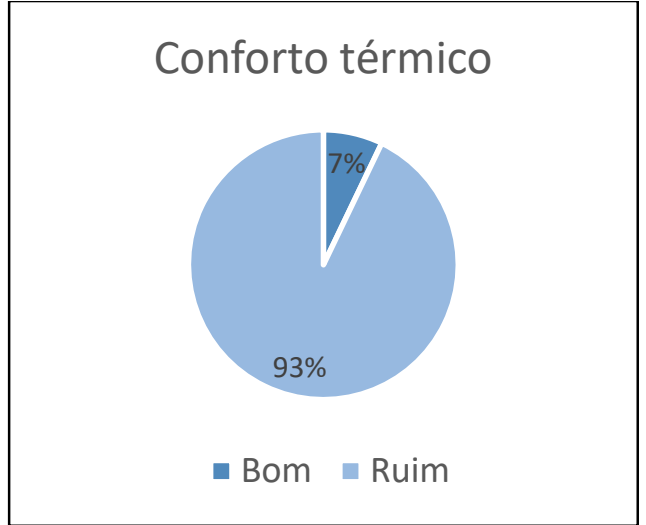

Figura 1: Percepção de conforto térmico nas habitações de interesse social dos bairros Residencial Jardim do Éden e Residencial Tiradentes.

\section{Problemas de Umidade}

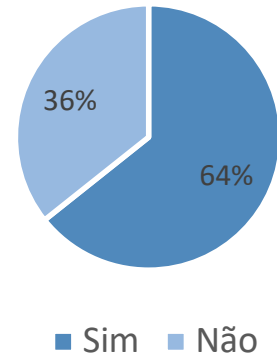

Figura 2: Percepção de problemas de umidade nas habitações de interesse social dos bairros Residencial Jardim do Éden e Residencial Tiradentes.

Com relação a satisfação térmica dos usuários, o questionário específico aplicado mostrou uma alta porcentagem de insatisfação com o conforto térmico das habitações analisadas. Dos 174 entrevistados, $82,2 \%$ responderam que a sensação térmica era sempre quente nos meses mais quentes (Figura 03) e 95,4\% afirmaram que gostariam que a temperatura estivesse mais fria (Figura 4).

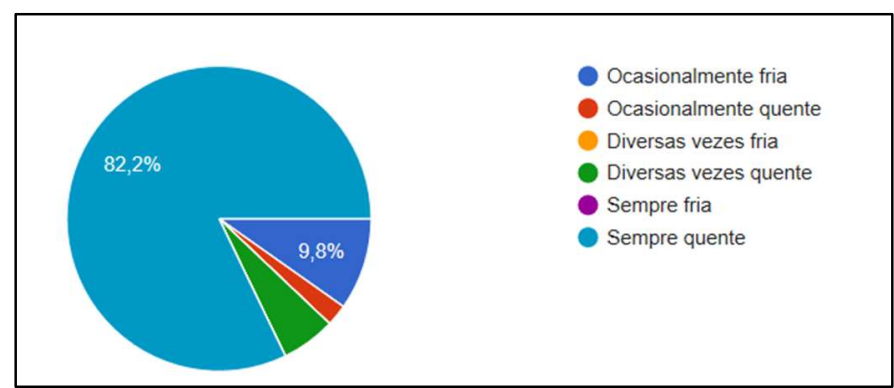

Figura 3: Percepção da sensação térmica nos meses mais quentes.

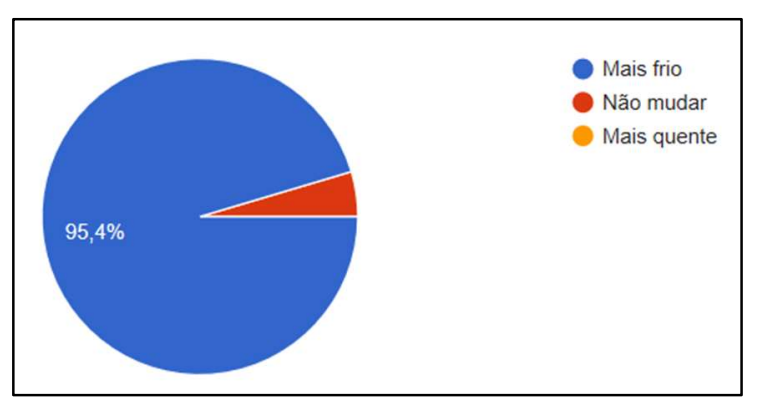

Figura 4: Índice de satisfação com a temperatura atual.

Os resultados encontrados podem ser justificados por problemas como a incidência solar direta em todas as paredes externas das residências, sendo poucas as que contavam com a presença de arvores ou arbustos próximos que propiciassem sombras adequadas. Além disso, foram relatados problemas como circulação de ar precária, falta de janelas e problemas com as já existentes, bem como o tamanho dos cômodos e a altura do pé direito muito baixo (Figura 5).

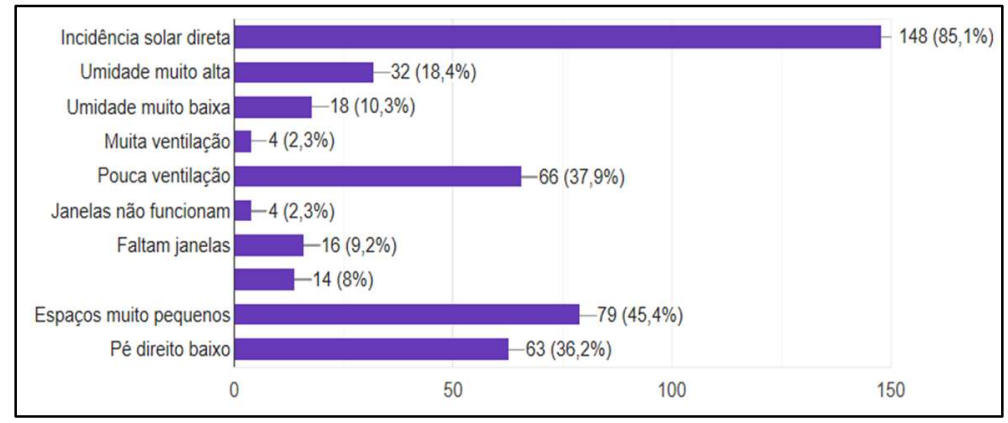

Figura 5: Principais fontes de desconforto térmico relatados. 
Diagnóstico técnico da infraestrutura pós-ocupação de regiões periféricas de marabá e proposta da criação de habitações de interesse social (HIS) nessas regiões

SILVA, B. V.; FERREIRA, L. M. P.; GALLARDO, N. P.; SILVA, D. C.

Vale ressaltar que, ao contrário de muitos exemplos negativos já presenciados em todo o país quanto ao estado de entrega e conservação das edificações, as casas entregues no município de Marabá apresentam condições estruturais adequadas, sem grandes patologias.

\section{CONCLUSÕES}

Considerando os resultados obtidos ao longo da pesquisa foi possível constatar que os principais problemas construtivos apontados foram relacionados ao conforto térmico e umidade em determinados períodos do ano. Isso ocorre, principalmente, em razão da simples replicação de projetos padrão por todo o país sem considerar fatores de influência locais, como a interação dos materiais selecionados com o clima do município recebedor dos projetos. Portanto, uma solução viável para adequação desses conjuntos habitacionais é propor a substituição de materiais de forma mais adequada a região.

Além disso, alterações no layout dos projetos como por exemplo a ampliação dos cômodos, aumento da altura do pé direito e a disposição mais eficiente de janelas auxiliariam no aumento da circulação de ar interna. É importante frisar a necessidade de investimento em criação de áreas verdes dentro dos terrenos utilizados nas HIS, focando em espécies capazes de propiciar sombras, de forma a reduzir a sensação térmica no entorno.

\section{REFERÊNCIAS}

SOUZA, M. V. M.. A produção do espaço urbano a partir do programa Minha Casa Minha Vida: inserção urbana e/ou desigualdades socioespaciais em Marabá/PA. Cerrados, v.14, n.2, p.30-51, 2016.

BONATTO, F. S.; FORMOSO, C. T.; MIRON, L. I. G.. Avaliação de empreendimentos habitacionais de interesse social com base na hierarquia de valor percebido pelo usuário. Revista da Associação Nacional de Tecnologia do Ambiente Construído, Porto Alegre, v.11, n.1, p.67-83, 2011.

BRANDÃO, D. Q.. Disposições técnicas e diretrizes para projeto de habitações sociais evolutivas. Ambiente Construído, v.11, n.2, p.73-96, 2011.

CONCEIÇÃO, P. A.; IMAI, C.; URBANO, M. R.. Captura e hierarquização de requisitos do cliente de habitação de interesse social a partir da avaliação pós-ocupação e da técnica de preferência declarada. Gestão \& Tecnologia de Projetos, v.10, n.1, p.83-102, 2015.

GRANJA, A. D.; KOWALTOWSKI, D. C. C. K.; PINA, S. A. M. G.; FONTANINI, P. S. P.; BARROS, L.; PAOLI, D.; JACOMIT, A. M.; MAÇANS, R. M. R.. A natureza do valor desejado na habitação social. Ambiente Construído, v.9, n.2, p.87-103, 2009.

HIRATA, F.. 'Minha Casa, Minha Vida': Política habitacional e de geração de emprego ou aprofundamento da segregação urbana?. Revista Aurora, v.2, n.2, 2009.

ROLNIK, R.; PEREIRA, A. L. S.; MOREIRA, F. A.; ROYER, L. O.; IACOVINI, R. F. G.; NISIDA, V. C.; LOPES, A. P. O.; ROSSI, L. G. A.. O Programa Minha Casa Minha Vida nas regiões metropolitanas de São Paulo e Campinas: aspectos socioespaciais e segregação. Cadernos Metrópole, v.17, n.33, p.127-154, 2015.

A CBPC - Companhia Brasileira de Produção Científica (CNPJ: 11.221.422/0001-03) detém os direitos materiais desta publicação. Os direitos referem-se à publicação do trabalho em qualquer parte do mundo, incluindo os direitos às renovações, expansões e disseminações da contribuição, bem como outros direitos subsidiários. Todos os trabalhos publicados eletronicamente poderão posteriormente ser publicados em coletâneas impressas sob coordenação da Sapientiae Publishing, da Companhia Brasileira de Produção Científica e seus parceiros autorizados. Os (as) autores (as) preservam os direitos autorais, mas não têm permissão para a publicação da contribuição em outro meio, impresso ou digital, em português ou em tradução. 